\title{
New knowledge of chondrocalcinosis
}

\author{
PAUL DIEPPE
}

From the Department of Medicine, University of Bristol

There are three varieties of cartilage-hyaline, elastic, and fibrocartilage. Hyaline cartilage is the precursor of bone. In the adult it is mainly found at bone ends, forming the load-bearing surface of synovial joints. Extra-articular fibrocartilages such as those of the trachea and ribs often calcify with advancing age. Articular cartilage, however, usually remains free from mineral deposits. The term 'chondrocalcinosis' may be defined as a pathological state characterised by the precipitation of insoluble calcium salts in articular and periarticular cartilage.

The presence of chondrocalcinosis can be proved only by crystallographic examination. Its presence may be inferred by radiological examination or the discovery of crystals in synovial fluid. In addition, articular chondrocalcinosis is sometimes accompanied by arthritis. There are therefore three separate phenomena associated with chondrocalcinosis-radiological changes, crystals in synovial fluid, and arthritis. These may occur separately or in any combination (Fig. 1).

The term 'chondrocalcinosis' was often used loosely in reference to radiological signs, the presence of pyrophosphate crystals in joints, or a characteristic form of arthritis. Recent work has highlighted the fact that many different crystals may be precipitated in cartilage and has led to a questioning of the causal relationship between crystals and arthritis. Further work would be aided by the use of a disciplined nomenclature-referring, for example, to articular pyrophosphate chondrocalcinosis-with a descriptive account of the associated features.

Calcium salts positively identified in human articular cartilage are: (1) calcium pyrophosphate dihydrate, $\mathrm{Ca}_{2} \mathrm{P}_{2} \mathrm{O}_{7} .2 \mathrm{H}_{2} \mathrm{O}$ (pyrophosphate, $\mathrm{CPPD}$ ); (2) hydroxyapatite, $\mathrm{Ca}_{10}\left(\mathrm{PO}_{4}\right)_{6} .(\mathrm{OH})_{2}$ (hydroxyapatite, apatite, HA); and (3) dicalcium phosphate dihydrate, $\mathrm{CaHPO}_{4} .2 \mathrm{H}_{2} \mathrm{O}$ (brushite, calcium phosphate dihydrate, DCPD).

Chondrocalcinosis may be classified according to (1) the nature of the deposit (pyrophosphate, hydroxyapatite, Brushite, or mixtures); (2) the type (familial, metabolic, sporadic, age associated); and (3) the metabolic associations: (a) hydroxyapatite (chronic renal disease); (b) pyrophosphate (hyper- parathyroidism, haemachromatosis, hypothyroidism, hypophosphataxia, hypomagnesaemia, gout(?), diabetes mellitus (?), Wilson's disease (?), ochronosis (?)).

\section{Historical perspective}

Intra-articular calcification has been recognised for at least a century. It was mentioned by Garrod (1876) and by Adams (1872). With the advent of joint radiography there were a number of reports of calcification of knee menisci (Pearson and Davin, 1921). Wolke (1935) described five cases from 2569 knee radiographs. Žitňan and Sitaj (1957) described 12 cases, and they later identified familial cases with polyarticular lesions and an associated arthritis (Žitňan and Siťaj, 1976).

While Žitňan and Sitaj surveyed joint radiographs Hollander and McCarty (1961) examined joint fluid by polarised light microscopy and discovered urate crystals in gout. McCarty et al. (1962) also noticed a different type of crystal in some patients with acute arthritis. They were identified by $x$-ray diffraction as calcium pyrophosphate dihydrate (CPPD) (Kohn et al., 1962).

Chondrocalcinosis has since been studied in various countries. Analysis of patients with radiological chondrocalcinosis by Currey (1966) and of those with pyrophosphate (PP) crystals in synovial fluid (Bjelle and Sundin, 1974) led to findings similar to those of Žitňan and Sitaj and of McCarty, who has now reported on over 300 cases (McCarty, 1976). A pattern emerges of patients with linear calcification of hyaline cartilage identified on $x$-ray examination, PP crystals in synovial fluid, and an arthritis that is either acute oligo- or mono-articular ('pseudogout') or chronic destructive, similar to osteoarthrosis ('chronic PP arthropathy'). Thus chondrocalcinosis becomes synonymous with PP deposition and its characteristic arthritis.

\section{New crystals}

McCarty and Gatter (1963) described the presence of dicalcium phosphate dihydrate in human fibro- 


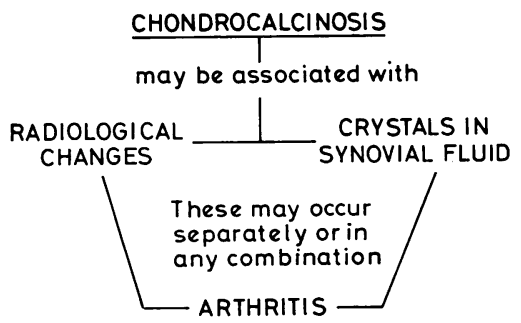

Fig. 1 Clinical association of chondrocalcinosis.

cartilage and, later, the pathological findings in 215 cadaver knee menisci (McCarty et al., 1966). Three salts were identified: calcium pyrophosphate dihydrate (CPPD) $(3.2 \%)$, dicalcium phosphate dihydrate (DCPD) $(2.3 \%)$, and hydroxyapatite (HA) $(1.4 \%)$. Vascular calcification in the outer onethird was also common (hydroxyapatite). Small unidentified deposits were seen in some specimens. No comprehensive study has been made on articular hyaline cartilage. Recently Ali (1977) has identified minute deposits of HA in osteoarthrotic hyaline cartilage, and Doyle et al. (1978) have made similar observations. Fibrocartilage seems to be peculiarly susceptible to PP deposits but hyaline cartilage may be more readily mineralised with $\mathrm{HA}$.

Both DCPD and HA have recently been described in the synovial fluid and tissues of patients with arthritis. Moskowitz et al. (1971), Faure et al. (1977), and Utsinger (1977) have described DCPD-related arthritis, and Dieppe et al. (1976) and Schumacher et al. (1976) HA-related arthropathy. Combinations of these different salts also occur. Moskowitz et al. (1971) identified a mixture of PP and DCPD, and mixtures of PP and HA have been found in the same joint by Okazaki et al. (1976) and Dieppe et al. (1978).

Sophisticated techniques are needed to identify the calcified deposits. Diffraction patterns provide precise crystal analysis, and both PP and DCPD have been identified in this way. HA crystals are usually too small for single crystal diffraction but powder patterns have been obtained. Other indirect ways of identifying these substances include infrared spectroscopy and analytical electron microscopy (Dieppe et al. 1977). Many workers have used electron microscopy with attached $x$-ray energy spectroscopy to calculate the ratio of calcium and phosphorus in different crystals compared with known standards. This technique, however, cannot differentiate PP from DCPD (Crocker et al., 1977; Nuki et al., 1978). Polarising microscopy is another indirect technique, ideal for differentiating gout from pseudogout. But small HA crystals cannot be seen by light micro- scopy, and many different salts may form the positively birefringent crystals usually assumed to be PP (Gatter, 1977).

Complex analytical techniques and tissue processing may alter the mineral content from that present in vivo. More crystallography studies are therefore required before conclusions can be reached about the incidence and nature of the different deposits of chondrocalcinosis. A scheme combining several different analytical techniques is shown in Fig. 2.

\section{Site of deposits}

Intra-articular calcification was always thought to comprise PP and periarticular mineral deposits of HA (McCarty and Gatter, 1966; Pinal and Short, 1966). In neither case is this always so.

Calcium salts of PP form monoclinic and triclinic crystals. The latter predominate. They are deposited preferentially in fibrocartilage. The commonest site is the knee meniscus, followed by the symphysis pubis, wrist, and intervertebral discs. Shoulders, elbows, hips, metacarpophalangeal, and other joints may also be affected. Linear calcification of tendons is not uncommon. A recent study reported an incidence of $13.5 \%$, the commonest sites being the tendo achilles, plantar fascia, and quadriceps tendon (Gerster et al., 1977). These periarticular deposits may be associated with inflammation but not all calcific periarthritis is due to HA.

The results of microscopy of PP-containing cartilage have varied. The most characteristic finding is of rounded deposits of crystals in a granular matrix in the mid-zone, often in a line along the cartilage, resulting in a linear shadow on the $x$-ray picture (Bjelle, 1972; Reginato et al., 1974). Crystals have also been identified in perichondrocyte lacunae (McCarty et al., 1963; Schumacher, 1976) and in superficial cartilage (Žitňan and Siťaj, 1966; de Sèze et al., 1963). It is tempting to postulate that the deposits around mid-zone chondrocytes (each crystal is only $250-500 \AA$ long) are the initial site of calcification and the superficial deposits the result of extensive loss of cartilage. Synovial deposits are also common in patients with PP chondrocalcinosis (Schumacher, 1976). These deposits are usually superficial and presumably come from the cartilage. Pachas (1972), however, has found deposits of PP in the synovium in the absence of chondrocalcinosis, raising the possibility of active deposition outside the cartilage. These studies have not resolved the important question of whether cartilage changes or crystal deposits occur first. Nor have they determined if there are any differences between familial, metabolic, and sporadic cases. 


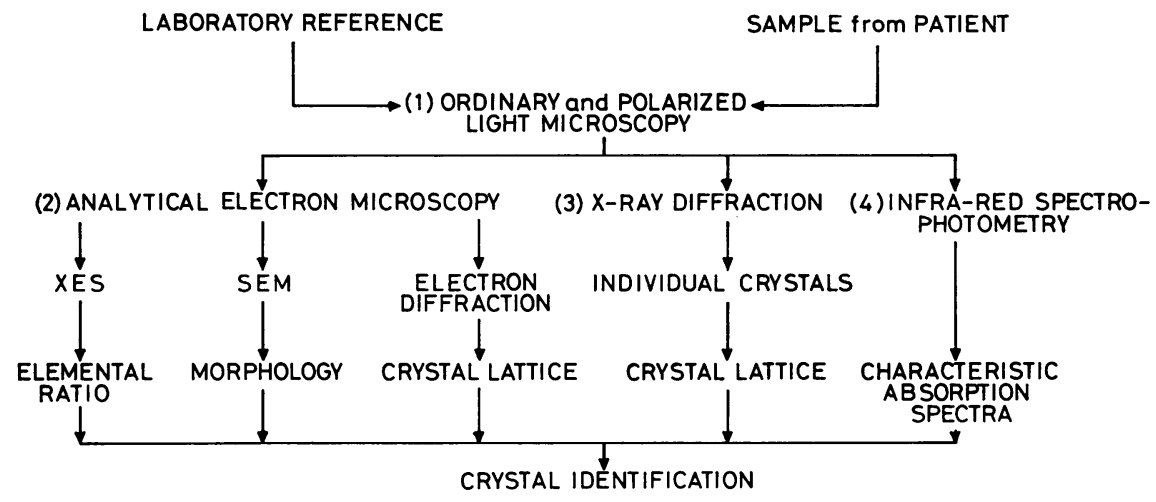

Fig. 2 Techniques for identifying crystals. XES = $\mathrm{x}$-ray energy spectrometry. SEM = scanning electron microscopy. All samples can be looked at by light microscopy (1). Processes (2), (3), (4) will be dependent on the type and size of sample available.

Growth cartilage calcifies by the formation of needle-shaped microcrystals of HA in matrix vasicles adjacent to chondrocytes (Ali and Wisby, 1975). Similar appearances have been noted in osteoarthrotic hyaline cartilage by Schumacher (1976), Ali (1977), and Doyle et al. (1978). Larger deposits of HA occur in the soft tissues of osteoarthrotic joints (Collins, 1949; Fassbender, 1975). We do not know whether these are 'seeded' from bony or cartilagenous fragments; from the HA crystals in cartilage; or whether, as could be the case with pyrophosphates, the soft tissues are a second site of active calcification. The joints affected are those affected by primary generalised osteoarthritis (Kellgren and Moore, 1952). In HA calcific periarthritis the affected joints are principally the shoulder and, to a lesser extent, the hip and others (Pinals and Short, 1S65).

Thus both HA and PP are found in articular and periarticular tissues. Although the sites of deposition differ, morphological studies have not clarified the mechanism of formation of these deposits.

\section{Metabolic background to chondrocalcinosis}

Crystallisation occurs only when there is both a high enough concentration of metabolites and the physical conditions to initiate nucleation. Much is known of the metabolism of calcium, phosphorus, and inorganic pyrophosphate but very little of the nucleation of their salts.

Inorganic pyrophosphate is formed by many metabolic processes throughout the body, principally by the breakdown of ATP. Serum and urine levels are not altered in the forms of arthritis that have been studied, but synovial fluid levels are high in both PP deposition and osteoarthritis (Russell et al., 1971; Altman et al., 1973; Silcox and McCarty, 1973). The origin of synovial PP may be the chondrocytes, which have been shown to liberate PP from in-vitro cultures of cartilage slices (Howell et al., 1976).
Nuki et al. (1978), however, have been unable to demonstrate this phenomenon using cultured monolayers of chondrocytes.

Additional sources of joint PP may include other cells, subchondral bone, and the crystals themselves. Breakdown of inorganic PP is a major source of simple phosphate radicals, a process accelerated by specific pyrophosphatases and by the alkaline phosphatase that is found in cartilage (Ali, 19/7). Calcium metabolism is in part controlled by parathormone. McCarty and O'Duffy (1976) have reported high levels of parathormone in both PP arthropathy and osteoarthrosis. Local levels of free calcium in cartilage may depend on proteoglycan binding, and loss of proteoglycans may predispose to calcification (Benderly and Maroudas, 1975). This argues in favour of chondrocalcinosis being secondary to cartilage damage. Proteoglycans are also a possible site of crystal nucleation, but the most likely site of formation of HA is the chondrocyte matrix vesicles (Ali et al., 1970; Ali, 1977).

The interrelationships between PP, DCPP, and HA seem complex. Pyrophosphate inhibits the formation of apatite and apatite formation is aided by alkaline phosphatase, itself a powerful pyrophosphatase (Fleisch et al., 1966). DCPD may be intermediary in the formation of HA.

The appearance of different salts in the same clinical situation and the coexistence of different salts in the same tissue is hard to explain. A simplified outline of some possible metabolic interrelationships, based on the work of Howell (1978), is shown in Fig. 3.

Most cases of PP deposition are idiopathic, but familial cases have been reported. A few may be secondary to other metabolic disease. The only unequivocal metabolic situation predisposing to apatite deposition is chronic renal failure (Canner and Decker, 1964; Lain et al., 1977). There is a long list of possible metabolic causes, but theyare difficult 


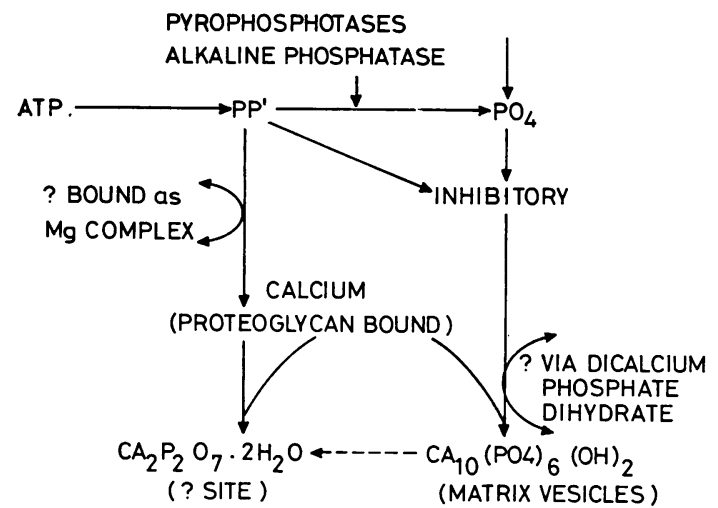

Fig. 3 Diagrammatic outline of some metabolic pathways participating in calcium crystal formation in cartilage.

to prove since only one controlled study has been made (McCarty et al., 1974). Investigation of the secondary causes of crystal deposition should aid understanding of the phenomenon. For example, Hamilton et al. (1968) have defined various special features of the disease when it is associated with haemachromatosis, an association which may be due to local deposits of iron aiding nucleation of PP crystals. Similarly, the association with hypomagnesaemia may be because magnesium ions normally bind inorganic PP. Hypophosphatasia causes PP deposits because of low levels of alkaline phosphatase (Eade and Swannell, 1977). The other associations of PP deposition have been reviewed by Hamilton (1976).

New aspects of features associated with chondrocalcinosis: radiological features

Wolke (1935) reported that $0.19 \%$ of a population surveyed radiologically showed evidence of chondrocalcinosis. Subsequent radiological surveys suggested that the incidence of chondrocalcinosis is nearer $5 \%$ (McCarty 1977). Recently Ellman and Levin (1975) studied an elderly Jewish population and found that $27.6 \%$ had chondrocalcinosis. These discrepancies

Table Relationship between radiological signs and type of crystal identified in synovial fluid in chronic arthritis

\begin{tabular}{lll}
\hline Radiological signs & \multicolumn{2}{l}{ Crystals identified } \\
\cline { 2 - 3 } & Pyrophosphate & Hydroxyapatite \\
\hline Linear calcification & 4 & 1 \\
Spotty calcification & 1 & 7 \\
None & 2 & 2 \\
\hline
\end{tabular}

are partly due to the different ages of the populations studied; chondrocalcinosis is more common in the elderly (Menin et al., 1977). Genant (1976) described the conditions necessary for good radiological visualisation. Gerster et al. (1977) documented the radiological signs of periarticular tendon calcification in patients with chondrocalcinosis, and Resnick et al. (1977) described the characteristic radiological features of chronic PP arthropathy that distinguish it from osteoarthritis.

Chondrocalcinosis usually results in a linear shadow in $x$-ray pictures. However, 'spotty' or rounded deposits are also seen, particularly in osteoarthritis where they are often described as 'loose bodies'. Analysis of the type of mineral in the tissues and synovial fluid of patients with linear or spotty deposits has shown that most linear deposits are associated with PP deposition and most spotty deposits with HA (Table) (Dieppe, 1978). However, the relationship is not perfect, re-emphasising that the nature of cartilage deposits should not be interpreted from radiographs alone.

\section{Crystals in synovial fluid}

PP and HA crystals are unlikely to precipitate directly in synovial fluid, but DCPD crystals may form in the fluid after its removal from the joints (Dieppe et al., 1978). Crystals deposited in cartilage may or may not appear in the synovial fluid. Bennett et al. (1976) postulated that they appear only in the presence of some 'factor' that increases solubility, decreasing the size of the deposit and resulting in 'crystal shedding' into the joint space. For these reasons, examination of synovial fluid cannot be regarded as a satisfactory method for detecting chondrocalcinosis.

Furthermore, accurate identification of crystals in synovial fluid is difficult. To be identified by light microscopy they must be at least $0.5 \mu \mathrm{m}$ long. The initial deposits of both PP and HA are much smaller. HA can be identified by analytical electron microscopy. I have mentioned the limitations of this technique but it has led to clear descriptions of HAinduced crystal synovitis (Dieppe et al., 1976; Schumacher et al., 1977) (Fig. 5). The lack of correlation between the numbers of crystals seen in synovial fluids and the clinical features of the arthritis, described by McCarty (1974a), has been a feature of our studies and remains unexplained.

\section{Arthritis}

McCarty (1974b) described four important clinical associations of PP deposition: 'pseudogout', 'pseudoosteoarthritis', 'pseudorheumatoid arthritis', and 
'pseudoneurotrophic joints'. The first two are the most common. Other conditions described include spinal stiffness (Reginato et al., 1970), haemarthrosis (Phelip et al., 1976), acute spinal pain, and polymyalgia rheumatica (Storey and Huskisson, 1976). PP crystals provoke inflammation (see below), and the synovitis of pseudogout is almostcertainly caused in this way (Schumacher, 1976).

The association between the presence of the crystals and the other forms of arthritis is obscure. Chondrocalcinosis is common but it is difficult to be certain of the significance of associations with common conditions. The association of chronic and destructive arthritis (Richards and Hamilton, 1974) with chondrocalcinosis is common but is unexplained. Žitňan and Sitaj (1976) have evidence that in familial cases chondrocalcinosis appears before chronic arthritis. But crystal deposition could be an epiphenomenon resulting from the same metabolic changes that cause the cartilage damage. The few reports of DCPD deposition suggest an association with a chronic destructive arthritis similar to chronic PP arthropathy (Moskowitz et al., 1971;
Faure et al., 1977; Utsinger, 1977).

HA crystals have been associated with four forms of arthritis-acute calcific periarthritis (Pinals and Short, 1966), osteoarthritis (Dieppe et al., 1976; Huskisson et al., 1978), synovitis in renal failure (Lain et al., 1977), and an acute arthritis (Schumacher et al., 1977). A causal relationship between the acute syndromes and the crystals seems reasonable in view of their inflammatory potential. Their role in osteoarthritis is not clear. Huskisson et al. (1978) and Ali (1978) have evidence of a link between HA deposition and osteoarthritis and, although probably a secondary phenomenon, it may explain some of the inflammatory features of this disease (Dieppe et al., 1978).

\section{Crystal-induced inflammation}

After PP crystals were identified experiments showed that they could cause acute inflammation (McCarty et al., 1966). HA crystals are also phlogistic (Dieppe et al., 1976; Denko and Whitehouse, 1976; Schumacher et al., 1976). PP crystals react with

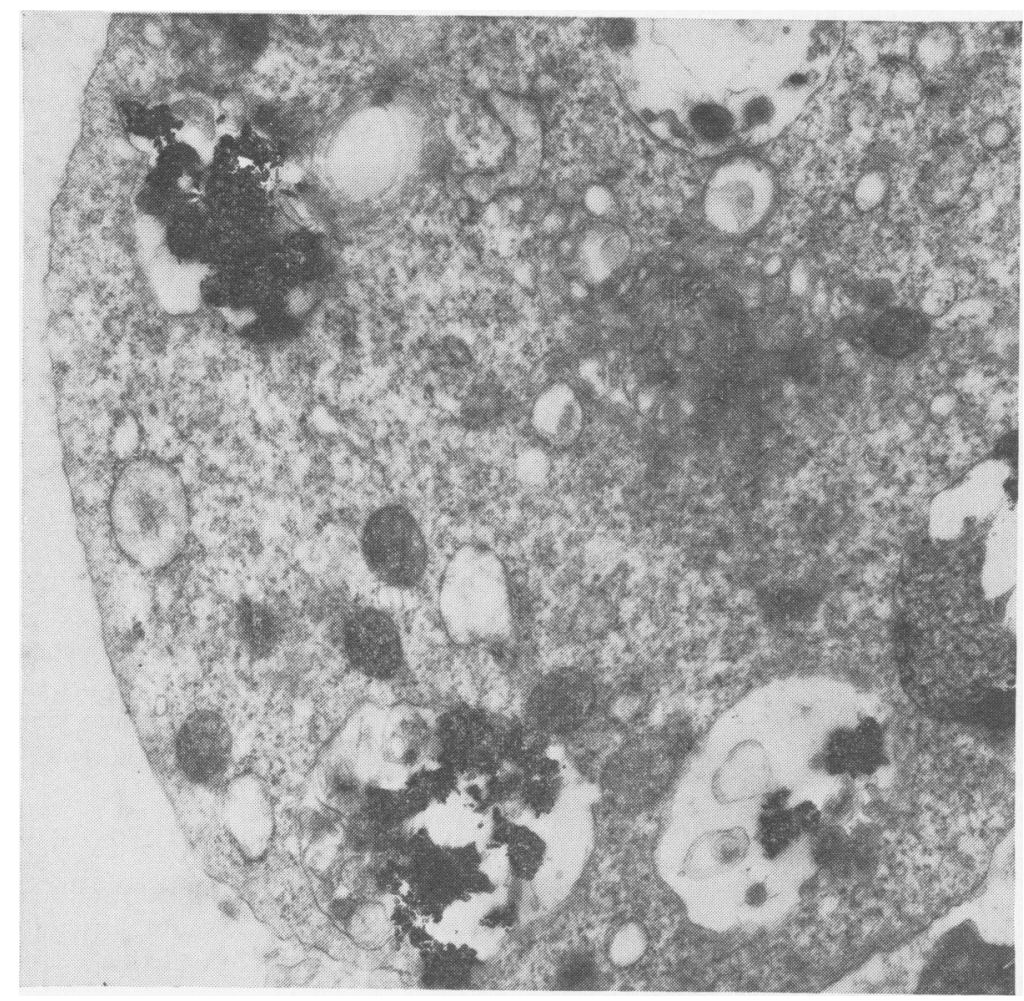

Fig. 4 Transmission electron micrograph of phagocytic cell from human osteoarthritic synovial fluid. Aggregates of hydroxyapatite crystals are seen within a phagosome. 


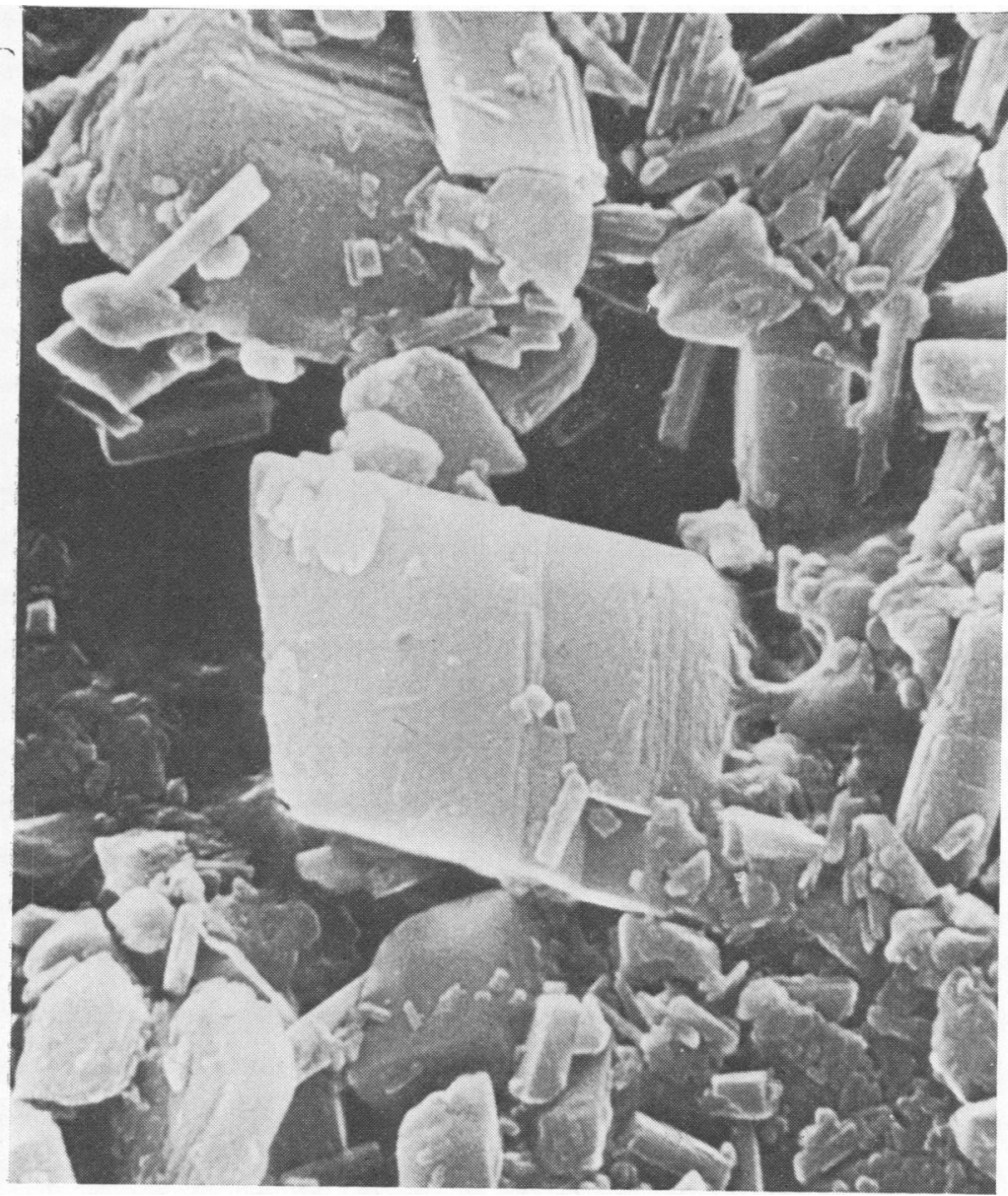

Fig. 5 Scanning electron micrograph of calcium pyrophosphate dihydrate crystals recovered from human osteoarthritic cartilage showing variation in size and shape of crystals. $(\times 125000)$

leucocytes, are phagocytosed (Tse and Phelps, 1970), have membranolytic activity (Wallingford and McCarty, 1971), and cause release of a chemotactic factor (Spilberg et al., 1975). These responses tend to be quantitatively less than with urate. The reaction is complement-independent and is mediated in a similar way to other forms of acute inflammation (Willoughby, 1975). Less is known about HA crystals. They are phagocytosed (Fig. 4) (Maurer and Schumacher, 1977) and can cause chronic as well as acute inflammation (Dunn et al., 1978).

Important determinants of the phlogistic properties of crystals include surface charge, the ability to bind protein (especially IgG), and crystal sizesmaller crystals are more inflammatory than larger (Dunn et al., 1978). Scanning electron microscopy has revealed a wide variety in size and shape of crystal deposits and this may have a bearing on clinical sequelae (Fig. 5). There have been recent reviews of some aspects of crystal-induced inflammation (Schumacher, 1977; Dunn et al., 1978; Allison, 1978). There is now considerable understanding of acute inflammation (and thus 'pseudogout' or acute calcific periarthritis) but little knowledge of how, if at all, crystals contribute to chronic disease.

\section{Conclusions}

Calcium pyrophosphate was thought of as the salt of chondrocalcinosis, but clearly many different calcium phosphates may be deposited in articular cartilage. Some cases are familial and a few secondary to metabolic disease, but in most there is no obvious cause for the calcification. Recent work on the pathology and metabolism of cartilage has drawn attention to its activity and the delicate balance between the activators and inhibitors of calcification. 
Chondrocalcinosis may be accompanied by three clinical phenomena-radiological changes, crystals in the synovial fluid, and arthritis. The application of new analytical techniques to the study of synovial fluid has enabled hydroxyapatite and other crystals to be identified and their presence correlated with radiological features and symptoms. Both hydroxyapatite and pyrophosphate crystals are inflammatory and acute synovitis can result from their presence in joints. Chondrocalcinosis, however, is more often associated with chronic joint disease, and in these cases calcification may be the clue to an underlying metabolic defect responsible for some forms of 'degenerative' arthritis.

\section{References}

Adams, R. (1873). A Treatise on Rheumatic Gout, 2nd edition. Churchill, London

Ali, S. Y., Sajdera, S. W., and Anderson, H. C. (1970). Isolation and characterisation of calcifying matrix vesicles from epipyseal cartilage. Proceedings of the National Academy of Sciences of the United States of America, 67, 1513-1520.

Ali, S. Y., and Wisby, A. (1976). The role of matrix vesicles in normal and osteoarthritic cartilage. Proceedings of the Royal Microscopical Society, 11, Pt 5, 62.

Ali, S. Y. (1977). Matrix vesicles and apatite nodules in arthritic cartilage. Perspectives in Inflammation, edited by D. A. Willoughby, J. P. Giroud, and G. P. Velo, pp. 211-223. MTP.

Ali, S. Y. (1978). In Aetiopathogenesis of Osteoarthritis, edited by G. Nuki. Pitman Medical, London, in press.

Allison, A. C. (1978). Effects of silica and asbestos on macrophages. European Journal of Rheumatology and Inflammation, in press.

Altman, R. D., Muniz, O., Pita, J. C., and Howell, D. S. (1973). Microanalysis of inorganic pyrophosphate (PP) in synovial fluid and plasma. Arthritis and Rheumatism, 16, 171-178.

Benderly, H., and Maroudas, A. (1975). Equilibria of calcium and phosphate ions in human articular cartilage. Annals of the Rheumatic Diseases, 34, Suppl. $2,46$.

Bennett, R. M., Lehr, J. R., and McCarty, D. J. (1976). Crystal shedding and acute pseudogout; an hypothesis based on therapeutic failure. Arthritis and Rheumatism, 19, 93-97.

Bjelle, A. O. (1972). Morphological study of articular cartilage in pyrophosphate arthropathy. Annals of the Rheumatic Diseases, 31, 449-456.

Bjelle, A. O., and Sunden, G. (1974). Pyrophosphate arthropathy: a clinical study of fifty cases. Journal of Bone and Joint Surgery, 56B, 246-255.

Canner, J. E. Z., and Decker, J. L. (1964). Recurrent acute arthritis in chronic renal failure treated with periodic dialysis. American Journal of Medicine, 36, 571-582.

Collins, D. H. (1949). The Pathology of Articular and Spinal diseases. Arnold, London.
Crocker, P. R., Dieppe, P. A., Tyler, G., Willoughby, D. A., and Chapman, S. K. (1977). The identification of particulate matter in biological tissues and fluids. Journal of Pathology, 121, 37-40.

Currey, H. L. F., Key, J. J., Mason, R. M., and Sweetenham, K. V. (1966). Significance of radiological calcification of joint cartilage. Annals of the Rheumatic Diseases, 25, 295-306.

Denko, C. W., and Whitehouse, M. W. (1976). Experimental inflammation induced by naturally occurring microcrystalline calcium salts. Journal of Rheumatology, 3, 54-62.

Dieppe, P. A. (1977). Crystal induced inflammation and osteoarthritis. In Perspectives in Inflammation, edited by D. A. Willoughby, J. P. Giroud, and G. P. Velo, pp. 225-231. MTP Press, Lancaster.

Dieppe, P. A. (1978). Calcium salt deposition in osteoarthritis. European Journal of Rheumatology and Inflammation, in press.

Dieppe, P. A., Crocker, P. R., and Willoughby, D. A. (1977). Microanalysis of particulate material involved in inflammation. In Perspectives in Inflammation, edited by D. A. Willoughby, J. P. Giroud, and G. P. Velo, pp. 233-235. MTP Press, Lancaster.

Dieppe, P. A., Huskisson, E. C., Crocker, P. R., and Willoughby, D. A. (1976). Apatite deposition disease, a new arthropathy. Lancet, 1, 266-269.

Dieppe, P. A., Huskisson, E. C., and Willoughby, D. A. (1978). The inflammatory component of osteoarthritis. In Aetiopathogenesis of Osteoarthritis, edited by G. Nuki. Pitman Medical, London, in press.

Dieppe, P. A., Doyle, D. V., Huskisson, E. C., Willoughby, D. A., and Crocker, P. R. (1978). Mixed crystal deposition disease and osteoarthritis. British Medical Journal, 1, 150-151.

Dieppe, P. A., Doyle, D. V., and Dunn, C. (1978). Unpublished observations.

Doyle, D. V., Dieppe, P. A., Huskisson, E. C., and Willoughby, D. A. (1978). Morphological Studies of Osteoarthritic Tissue, in press.

Dunn, C., Doyle, D. V., and Willoughby, D. A. (1978). A review of the experimental methods and associated problems in the study of crystal deposition disease. European Journal of Rheumatology and Inflammation, in press.

Ellman, M. H., and Levin, B. (1975). Chondrocalcinosis in elderly persons. Arthritis and Rheumatism, 18, 43-47.

Fassbender, H. G. (1975). Pathology of Rheumatic Diseases. Springer-Verlag, Berlin.

Faure, G., Netter, P., Malanan, B., and Steinmetz, J. (1977). Monocrystalline calcium hydrogen phosphate dihydrate in destructive arthropathy of chondrocalcinosis. Lancet, 2, 142-143.

Fleisch, H., Maerki, J., and Russell, R. G. G. (1966). Effect of pyrophosphate on dissolution of hydroxyapatite and its possible importance in calcium homeostasis. Proceedings of the Society for Experimental Biology, 122, 317-320.

Garrod, A. B. (1876). A Treatise on Gout and Rheumatic Gout. Longmans Green, London.

Gatter, R. A. (1977). Use of the compensated polarizing microscope. Clinics in Rheumatic Diseases, 3, No. 1, 
91-103.

Genant, H. (1976). Roentgenographic aspects of calcium pyrophosphate dihydrate crystal deposition disease. Arthritis and Rheumatism, 19, 307-328.

Gerster, J. C., Baud, C. A., Lagier, R., Boussina, I., and Fallet, G. H. (1977). Tendon calcifications in chondrocalcinosis. Arthritis and Rheumatism, 20, 717-722.

Hamilton, E. B. D. (1976). Diseases associated with CPPD deposition disease. Arthritis and Rheumatism, 19, 353-358.

Hamilton, E. B. D., Williams, R., Barlow, K. A., and Smith, P. M. (1968). The arthropathy of idiopathic haemachromatosis. Quarterly Journal of Medicine, 37, 171-182.

Howell, D. S. (1978). In Aetiopathogenesis of Osteoarthritis, edited by G. Nuki. Pitman Medical, London, in press.

Howell, D. S., Muniz, O., Pita, J. C., and Enis, J. E. (1976). Pyrophosphate release by osteoarthritis cartilage incubates. Arthritis and Rheumatism, 19, 488-494.

Huskisson, E. C., Dieppe, P. A., and Tucker, Cannell A. (1978). A New Look at Osteoarthritis, in press.

Kellgren, J. H., and Moore, R. (1952). Generalised osteoarthritis. British Medical Journal, 1, 181-184.

Kohn, N. N., Hughes, R. E., McCarty, D. J., and Faires, J. S. (1962). The significance of calcium phosphate crystals in the synovial fluid of arthritic patients: the 'pseudogout syndrome'. II Identification of crystals. Annals of Internal Medicine, 56, 738-745.

Eade, A. W. T., and Swannell, A. J. (1977). Pyrophosphate arthropathy in hypophosphatasia. XIV International Congress of Rheumatology. Abstract 424.

Lain, D., Thorne, G., and Steigerwald, J. C. (1977). Calcium hydroxyapatite as a cause of arthropathy in patients with renal disease. XIVth International Congress of Rheumatology. Abstracts 433.

Maurer, K. H., and Schumacher, H. R. (1977). Hydroxyapatite phagocytosis by human leucocytes. XIV International Congress of Rheumatology. Abstract 437.

McCarty, D. J. (1974a). Crystal deposition joint disease. Annual Review of Medicine, 279-288.

McCarty, D. J. (1974b). Diagnostic mimicry in arthritis. Patterns of joint involvement associated with CPPD deposits. Bulletin on Rheumatic Diseases, 25 (5), 804809.

McCarty, D. J. (1976). Calcium pyrophosphate dihydrate crystal deposition disease-1975. Arthritis and Rheumatism, 19, 275-285.

McCarty, D. J. (1977). Clinical aspects of calcium pyrophosphate dihydrate deposition disease. Clinics in Rheumatic Diseases, 3, 61-89.

McCarty, D. J., and Gatter, R. A. (1962). Pseudogout syndrome. III Articular calcifications. Occurrence, distribution, and identity with crystals found in synovial fluids. Arthritis and Rheumatism, 5, 652-663.

McCarty, D. J., and Gatter, R. A. (1966). Recurrent acute inflammation associated with focal apatite crystal deposition. Arthritis and Rheumatism, 9, 804819.

McCarty, D. J., and Hollander, J. L. (1961). Identification of urate crystals in gouty synovial fluid. Annals of Internal Medicine, 54, 452-460.
McCarty, D. J., and O'Duffy, J. D. (1976). Discussion on parathormone levels in chondrocalcinosis and osteoarthritis. Arthritis and Rheumatism, Suppl., 19, 360.

McCarty, D. J., Gatter, R. A., and Hughes, R. E. (1963). Pseudogout syndrome. IV. Early and 'mature' cartilagenous deposits of monoclinic and triclinic crystals of calcium pyrophosphate dihydrate: Koch's postulates and possible pathogenesis. Arthritis and Rheumatism, 6, 287-299.

McCarty, D. J., Silcox, D. C., Coe, F., Jacobelli, S., Reiss, J., Genant, H., and Ellman, R. (1974). Diseases associated with calcium pyrophosphate dihydrate crystal deposition. American Journal of Medicine, 56, 704-714.

McCarty, D. J., Kohn, N. N., and Faires, J. S. (1962). The significance of calcium phosphate crystals in the synovial fluid of arthritis patients: the 'pseudogout syndrome'. I clinical aspects. Annals of Internal Medicine, 56, 711-737.

McCarty, D. J., Hogan, J. M., Gatter, R. A., and Grossman, M. (1966). Studies in pathological calcifications in human cartilage. I Prevalence and types of crystal deposits in the menisci of two hundred fifteen cadavera. Journal of Bone and Joint Surgery, 48(A), 309-325.

McCarty, D. J., Phelps, P., and Pyenson, J. (1966). Crystal-induced inflammation in canine joints 1 . An experimental model with quantification of the host response. Journal of Experimental Medicine, 124, 99114.

Menin, Y., Monville, C., and Ryckewaert, A. (1977). Chondrocalcinosis over 80 . XIVth International Congress of Rheumatology. Abstract 438.

Moskowitz, R. W., Harris, B. K., Schwartz, A., and Marshall, G. (1971). Chronic synovitis as a manifestation of calcium crystal deposition disease. Arthritis and Rheumatism, 14, 109-116.

Nuki, G., Pritchard, M. H., Henderson, W. J., and Lust, G. (1978). Articular cartilage mineralisation and inorganic pyrophosphate metabolism in chondrocytes. European Journal of Rheumatism and Inflammation, in press.

Okazaki, T., Saito, T., Mitomo, T., and Siota, Y. (1976). Pseudogout: clinical observations and chemical analysis of deposits. Arthritis and Rheumatism, Suppl., 19, 293-305.

Pachas, W. N. (1972). Pseudogout without chondrocalcinosis: a clinical, radiologic and pathologic study of 18 cases. Arthritis and Rheumatism, 15, 121-122.

Pearson, K., and Davin, A. G. (1921). On the sesamoids of the knee-joint. Biometrica, 13, 133-137.

Pinals, R. S., and Short, C. L. (1966). Calcific periarthritis involving multiple sites. Arthritis and Rheumatism, 9, 566-574.

Phelip, X., Verdier, J. M., Gras, J. P., Mouries, D., Blanc, D., Gintz, B., and Cabanel, G. (1976). Les hémarthroses de la chondrocalcinose articulaire et de Maladies Osteo-articulaires. Revue de Rheumatisme, 43, 259-266.

Reginato, A. J., Schumacher, H. R., and Martinez, V. A. (1974). The articular cartilage in familial chondrocalcinosis. Light and electron microscopic study. Arthritis and Rheumatism, 17, 977-992. 
Reginato, A. J., Valuenzela, F., Martinez, V. A., Passano, G., and Daza, S. (1970). Polyarticular and familial chondrocalcinosis. Arthritis and Rheumatism, 13, 197. 213.

Resnick, D., Niwayama, G., Goergen, T., Utsinger, P. D., and Shapiro, R. (1977). The incidence and specificity of pyrophosphate arthropathy. XIVth International Congress of Rheumatology. Abstract 444.

Richards, A. J., and Hamilton, E. B. D. (1974). Destructive arthropathy in chondrocalcinosis articularis. Annals of the Rheumutic Diseases, 33, 196-203.

Russell, R. G. G., Bisaz, S., Donath, A., Morgan, D., and Fleisch, H. (1971). Inorganic pyrophosphate in plasma in normal persons and in patients with hypophosphatasia, osteogenesis inperfecta and other disorders of bone. Journal of Clinical Investigation, 50, 961-969.

Schumacher, H. R. (1976). Ultrastructural findings in chondrocalcinosis and pseudogout. Arthritis and Rheumatism, 19, 413-425.

Schumacher, H. R. (1977). Pathogenesis of crystalinduced synovitis. Clinics in Rheumatic Diseases, 3, 105-131.

Schumacher, H. R., Tse, R., Reginato, A., Miller, A. J., and Maurer, K. (1976). Hydroxyapatite-like crystals in synovial fluid cell vacuoles. A suspected new cause for crystal-induced arthritis. Arthritis and Rheumatism, 19, 821.

Schumacher, H. R., Smolyo, A. P., Tse, R., and Maurer, K. (1977). Arthritis associated with apatite crystals. Annals of Internal Medicine, 87, 411-416.

de Sèze, S., Fressinaud, L., Besson, J., Mazabraud, A., and Mitrovic, D. (1963). Etude anatomoclinique d'un cas de chondrocalcinose articulare diffuse. Semaine des Hôpitaux de Paris, 39, 1515-1521.

Silcox, D. C., and McCarty, D. J. (1973). Elevated in- organic pyrophosphate concentrations in synovial fluids in osteoarthritis and pseudogout. Journal of Laboratory and Clinical Medicine, 83, 518-531.

Spilberg, I., Gallacher, A., and Mandell, B. (1975). Cellular localization of calcium pyrophosphate dihydrate crystal (CPPD) induced chemotactic factor: role of phagocytosis. Arthritis and Rheumatism, 18, 427.

Storey, G. O., and Huskisson, E. C. (1977). Unusual presentations of pyrophosphate arthropathy. British Medical Journal, 2, 21-22.

Tse, R. L., and Phelps, P. (1970). Polymorphonuclear leukocyte motility in vitro. V Release of chemotactic activity following phagocytosis of calcium pyrophosphate crystals, diamond dust and urate crystals. Journal of Laboratory and Clinical Medicine, 76, 403415.

Utsinger, P. D. (1977). Dicalcium phosphate dihydrate deposition disease: a suspected new crystal induced arthritis. XIVth International Congress of Rheumatology, Abstracts, 448.

Willoughby, D. A. (1975). Human arthritis applied to animal models: towards better therapy. Annals of the Rheumatic Diseases, 34, 471-478.

Wallingford, W. R., and McCarty, D. J. (1971). Differential membranolytic effects of microcrystalline sodium urate and calcium pyrophosphate dihydrate. Journal of Experimental Medicine, 133, 100-112.

Wolke, K. (1935). Über Meniskus-und Gelenkknorpelverkalkungen. Acta Radiolica, 16, 577-588.

Žitňan, D., and Siťaj, S. (1957). Calcifications multiples du cartilage articulaire. Ninth International Congress on Rheumatic Diseases, Toronto.

Žitn̆an, D., and Sitaj, S. (1976). Natural course of articular chondrocalcinosis. Arthritis and Rheumatism, 19, Suppl., 363-390. 